\title{
Planejamento estratégico de uma instituição de ensino superior federal brasileira: uma análise à luz do movimento da governança pública
}

\section{Strategic Planning of a brazilian higher education institution: an analysis under the theory of public govenance}

\author{
SARA ABREU HENN* \\ JACIR LEONIR CASAGRANDE** \\ NEI ANTONIO NUNES*** \\ ANDRÉ LUIS DA SILVA LEITE**** \\ ICARO PICOLLI*****
}

\section{RESUMO}

Este artigo procura analisar o processo de elaboração e execução do planejamento estratégico de uma instituição de ensino superior federal à luz dos critérios de planejamento calcados na concepção de governança pública, dando ênfase a preceitos como equidade e desenvolvimento regional. Sob o ponto de vista metodológico, trata-se de uma pesquisa de caráter exploratório-descritivo, de abordagem predominantemente qualitativa. Para a coleta de dados primários foram realizadas entrevistadas semiestruturadas com os principais responsáveis pelo planejamento da instituição, em duas gestões subsequentes. Como dados secundários, foram analisados os principais docu-

* Contadora pela UFSC. Mestre em Administração pela UNISUL.

E-mail: sarahenn@hotmail.com.

* Doutor em Engenharia de Produção pela UFSC. Professor do Programa de Pós-Graduação em Administração da UNISUL. E-mail: Jacir.unisul@gmail.com.

*** Doutor em Ciência Política pela UFSC. Professor do Programa de Pós-Graduação em Administração da UNISUL. E-mail: neinunes@bol.com.br

**** Doutor em Engenharia de Produção pela UFSC. Professor do Depto. De Ciências da Administração da UFSC. E-mail: andre.leite@live.com

***** Mestrando em Administração na UNISUL. E-mail:icaropicolli@gmail.com 
mentos da instituição relacionados ao processo de planejamento estratégico. Os resultados obtidos demonstram que tal processo é realizado de forma participativa com o envolvimento das principais instâncias da organização (alunos, professores e técnicos administrativos). Contudo - e mesmo que existam traços do movimento de governança pública no processo de planejamento estratégico da instituição -, seu planejamento está mais voltado para resultados em uma perspectiva gerencialista, o que reduz o peso e a participação da sociedade.

Palavras-chave: Governança pública; planejamento estratégico; administração pública; gestão universitária

\section{Abstract}

This article seeks to analyse the process of preparation and implementation of the strategic planning of a federal institution of higher education in the light of the planning criteria based on conception of public governance, emphasizing the precepts as equity and regional development. Under the methodological point of view, this is a survey of exploratory-descriptive, predominantly qualitative approach. For the collection of primary data were carried out along the main semi-structured interviewed who are responsible for planning the institution, in two subsequent administrations. As secondary data, we analyzed the main documents related to the institution's strategic planning process. The results obtained show that the planning process is carried out in a participative manner with the involvement of the main instances of organization (students, teachers and administrative technical). However -and even if there are traces of the movement of public governance in the process of strategic planning of the Institution - the planning is more focused on results in a managerial perspective, which reduces the weight and the participation of society.

Keywords: Public governance; strategic planning; public management; university management.

\section{INTRODUÇÃo}

Embora o desenvolvimento de uma sociedade esteja vinculado aos resultados econômicos oriundos das atividades produtivas, percebe-se claramente - como indica, por exemplo, Antonio Gramsci 
(COUTINHO, 2011) - que o desenvolvimento social está na sociedade civil, mas transcende o espectro do mercado. Bastante próximo ao que dirá Hegel (2000), Ramos (1989) adverte que no mercado perpassam interesses individuais arraigados da intenção de maximização dos resultados, daí a importância do Estado como dimensão que pode garantir a expressão dos valores sociais e a delimitação do mercado como esfera que deve ser politicamente regulada.

De certo modo, o papel do Estado deve ser pautado na construção de um sistema político que sirva à sociedade no sentido multicêntrico e numa perspectiva paraeconômica, como vem sendo demandado pela sociedade do século XXI (RAMOS, 1989). Nessa perspectiva, o movimento de governança pública contribui para que o Estado possa se configurar como o coordenador executivo de um projeto de desenvolvimento baseado na visão integrada dos atores sociais - além do próprio Estado, o mercado e a sociedade civil.

Contudo, Ramos (1989) aponta para a necessidade de mudança no padrão mental dos administradores públicos que coordenam a elaboração e a execução de um projeto de desenvolvimento, ou seja, o abandono da sistemática baseada na lógica de mercado e a adoção de uma sistemática revestida da perspectiva multicêntrica de intervenção estatal. Visando a contribuir com as problemáticas já propostas por Ramos, Dias (2012) e Cario e Dias (2014) sugerem que, no movimento de governança pública, localizam-se potencialidades que podem fazer com que o Estado possa ser o coordenador de um projeto de desenvolvimento pautado numa perspectiva multicêntrica e paraeconômica, o que permitiria afastar a sociedade moderna dos efeitos mais deletérios da unidimensionalidade.

Denhardt (2012) destaca ainda que a estrutura do Estado e as organizações que a compõem influenciam o desenvolvimento e os resultados das diversas políticas. O autor enfatiza que o processo político deve estar permeado por reflexões acerca da correspondência entre as decisões dos burocratas (administradores públicos) e o que é de interesse da sociedade. Seria preciso também inquirir e melhor avaliar a capacidade do sistema de governo em planejar projetos e ações exequíveis.

Dessa forma, as organizações públicas devem planejar suas ações de maneira a contribuir com o desenvolvimento da região e 
do contexto em que se inserem. Na matriz de elementos que caracterizam a gênese do movimento de mudança para governança pública - conforme Dias (2012), Cario e Dias (2014) - estão delineados os pontos centrais dessa concepção de governança. O planejamento configura-se, assim, como um dos elementos e deve ser voltado à equidade e ao desenvolvimento regional. Para os autores, a ideia de equidade está relacionada à capacidade do Estado de conceber projetos, programas e políticas públicas, levando em consideração a evolução divergente de cada região administrativa e, portanto, as suas diferentes demandas.

O desenvolvimento regional vincula-se à concepção de governança pública que atrela a dimensão estatal ao desenvolvimento do poder local e/ou regional, uma vez que o envolvimento ativo dos cidadãos na resolução dos problemas coletivos se dá no âmbito da comunidade ou região (DIAS, 2012; CARIO; DIAS, 2014).

Levando em conta estas considerações, decidiu-se orientar o presente estudo com base na seguinte pergunta de pesquisa: como a instituição de ensino superior federal pesquisada tem adotado a perspectiva de governança pública no processo de elaboração e execução do seu planejamento estratégico?

Nessa investigação, tem-se como objetivo principal analisar o processo de elaboração e execução do planejamento estratégico da instituição de ensino superior federal pesquisada à luz de critérios de planejamento abordados na concepção de governança pública.

Para atingir o objetivo geral, apresentam-se os seguintes objetivos específicos: i) conhecer o processo de elaboração e execução do planejamento estratégico da instituição de ensino superior pesquisada; ii) investigar as características de governança pública na elaboração e/ou execução do planejamento estratégico da instituição de ensino superior pesquisada; e iii) Apontar recomendações de melhoria na elaboração e/ou discussão do planejamento estratégico da instituição de ensino superior pesquisada à luz do movimento de governança pública.

A pertinência deste estudo está na relevância social e científica da temática abordada, daí a necessidade de avanço teórico e empírico sobre o objeto ora investigado. Como assevera Raquel (2012, p. 77), “a elaboração de estudos teórico-empíricos pode proporcionar 
reflexões para compreender até que ponto um modelo de gestão pública, neste caso da governança pública, pode ser encontrado nas atividades da administração pública". Aliás, a matriz de elementos que caracterizam a gênese do movimento de mudança para governança pública, indicada em Dias (2012) e Cario e Dias (2014), revela que o planejamento é voltado à equidade e ao desenvolvimento regional, traduzindo a ideia de que a Administração Pública deve pautar seu planejamento nesses preceitos. E mais, os autores sugerem que os mecanismos da democracia representativa devem se institucionalizar em nível local e regional, uma vez que questões sociais específicas tendem a ser mais adequadamente resolvidas pelos atores nelas envolvidos.

O estudo está estruturado do seguinte modo: a introdução, que apresentou uma breve contextualização sobre o tema, o referencial teórico, a metodologia, os resultados da pesquisa e, ao final, as considerações finais.

\section{REFERENCIAL TEÓRICO}

\subsection{A emergência do movimento}

Ao longo do século XIX, o sistema político tinha caráter liberal e a Administração Pública se configurava patrimonialista. O Estado atuava como extensão do poder da monarquia, e os servidores públicos eram, de certo modo, considerados nobres. Para Motta (2007, p. 88), o patrimonialismo na Administração Pública é “[...] a forma de organização e gestão em que obedecia baseado nos critérios técnicos racionais e democráticos para a prestação de serviços e mais a sistemas de loteamento político, para manter coalizões de poder e atender a grupos preferenciais". Já na organização burocrática, a autoridade está baseada em normas racionais legais, onde as competências são ordenadas por regras fixas. (RAQUEL, 2012).

As disfunções do modelo burocrático, juntamente com os problemas do sistema capitalista, principalmente os oriundos da crise fiscal da década de 1970, trazem à tona novas demandas sociais relacionadas à estrutura das organizações públicas que demonstram incapacidade para solucionar alguns problemas públicos e são compreendidas no contexto de um Estado inchado e inoperante (BEVIR, 2010). 
Assim, enquanto parte dos estudiosos, aproveitando a crise do Estado que se instalou a partir das décadas de 1970 e 1980, optou por reforçar os ideais da lógica de mercado como sistema perfeito para dar conta do desenvolvimento econômico e forjar o pensamento neoliberal, outra parte optou por interpretar esse novo contexto como um reforço ao pensamento desenvolvimentista (DIAS, 2012; CARIO; DIAS, 2014).

A redefinição do papel do Estado tem como pano de fundo a ideia de que a preocupação com a Administração Pública se dá em benefício da sociedade civil e o foco deixa de ser os processos e resultados, passando o interesse público e a noção de coletividade a ser as principais preocupações.

\subsection{Governança pública}

A concepção de governança pública partilha, de certo modo, da convicção de que o Estado deixa de ser o principal responsável das decisões e ações políticas e administrativas, assumindo, sobretudo, o papel de articulador. Conforme Dias (2012, p. 103), “Governança Pública é assim um movimento que surge na Administração Pública do Estado neodesenvolvimentista com a proposta de promover a reintegração da política com a administração e como instrumento de processos mais democráticos". Dessa forma, entende-se que o movimento de governança pública considera a participação dos atores sociais, levando à Administração Pública elementos da vida política. Nessa perspectiva, as decisões são tomadas por meio de instrumentos mais democráticos.

Acrescenta Dias (2012) que a governança pública pode ser considerada como um movimento que se reconhece como um jeito de governar em que a cooperação é o fio condutor do desenvolvimento que cada esfera social deseja, sendo coordenado pelo Estado, porém com menos governo e mais governança. O Quadro 1 a seguir demonstra os elementos que caracterizam essa posição. 
Quadro 1: Matriz de elementos que caracterizam a gênese do movimento de mudança para governança pública

\begin{tabular}{|c|l|}
\hline \multicolumn{2}{|c|}{ Elementos da concepção de Governança Pública } \\
\hline E1 & $\begin{array}{l}\text { Coprodução do desenvolvimento regional por meio da cooperação entre } \\
\text { Estado, mercado e sociedade civil. }\end{array}$ \\
\hline E2 & $\begin{array}{l}\text { Coordenação estatal do processo de cooperação, tendo o Estado um papel de } \\
\text { mediador das relações. }\end{array}$ \\
\hline E3 & $\begin{array}{l}\text { Delegação da autoridade estatal em três direções: downward, outward e } \\
\text { upward, reconhecendo o potencial e incentivando o papel das redes. }\end{array}$ \\
\hline E4 & $\begin{array}{l}\text { Enfase na eficiência e eficácia associando-as a mecanismos de democracia } \\
\text { deliberativa e democracia direta para a busca de resultados responsivos. }\end{array}$ \\
\hline E5 & Planejamento com vistas à equidade e ao desenvolvimento regional. \\
\hline
\end{tabular}

Fonte: Dias (2012).

Como indicado, o E5 (Planejamento com vistas à equidade e ao desenvolvimento regional) será analisado a partir do processo de planejamento estratégico de uma instituição de ensino superior pública - com o intuito de verificar a relação dos constructos investigados nesta seção teórica com as ações planejadas - como órgão representante das políticas públicas em educação superior no Brasil, em nível regional.

Bevir (2010) dá enfase à governança pública como um movimento que, a partir da análise mais pluralista do Estado, busca novas formas de fazer e legitimar as políticas públicas sob a ótica de uma perspectiva democrática. Dessa perspectiva, é possível inferir que esse movimento traz à Administração Pública a ideia de que a ciência política e a administração pública caminham juntas e são interdependentes. Como decorrência, depreende-se que é possível a criação de espaços institucionais/sociais mais democráticos que permitam a implementação de políticas públicas na Administração Pública.

Kissler e Heidemann (2006) discutem o papel do Estado e conceituam os pressupostos da governança pública como um Estado estratégico, o qual transforma seu papel em três sentidos: i) de um Estado de serviço e produtor do bem público para outro que serve de garantia à produção do bem público; ii) de um Estado ativo e provedor solitário para outro, ativador e coordenador das relações dos atores para que produzam com ele; e iii) de um Estado dirigente ou gestor para outro, cooperativo, em que o bem público é produzido em conjunto. 
Esse esforço analítico contribui para que melhor se compreendam as mudanças ocorridas no Estado; ou seja, Estado tradicional vem paulatinamente se transformando e deixa de ser o principal responsável pela formulação de políticas públicas, passando a compartilhar essa responsabilidade. Aos poucos, deixa a condição de produtor do bem público e transforma-se num agente garantidor da sua produção. Dito de outro modo, em vez de prover sozinho o bem público, coordena outros atores para, em conjunto, realizarem esta produção. Torna-se, portanto, um Estado ativador, um ente cooperativo.

\subsection{Planejamento estratégico na Administração Pública}

No cenário público, pela ausência de competitividade nos monopólios estatais e de outras formas de se mensurar desempenho, a percepção e o senso de utilidade de adoção do planejamento estratégico, como usualmente aplicado em ambientes competitivos, podem ser diferentes. Nesse sentido, a utilização de planejamento estratégico no setor público é mais recente que na esfera privada e, nos últimos anos, seu uso vem crescendo gradualmente (PEREIRA, 2006).

Há na literatura certa escassez de publicações que relacionem o planejamento estratégico no contexto da Administração Pública. Segundo Gueraldi (2006), “a literatura no âmbito estratégico que trata da perspectiva da interface entre os setores público e privado é escassa (PAULA, 2005; GETZ, 2002; MINTZBERG, 1996; FERLIE, 2002; 1992)".

ConformeWright, Kroll e Parnell (2000), entre as principais características estratégicas das organizações públicas destacam-se: o caráter de indispensabilidade da manutenção de uma sociedade civilizada; o necessário suprimento das necessidades básicas da sociedade que não podem ser satisfeitas pelas organizações privadas; e a disponibilidade de produtos e serviços a todos os membros da sociedade.

Giacobbo (1997) afirma ainda que as características presentes nas instituições públicas e que dificultam a implementação do planejamento estratégico são: fidelidade ao passado, modelo de gestão centralizado, lentidão no processo decisório, imobilismo, privilégios estabelecidos etc. $\mathrm{O}$ autor também afirma que, devido à estrutura complexa e ao rigor burocrático nessas instituições, "a 
formalização do processo de planejamento (cronograma, manuais, definição de responsabilidades) e dos planos é muito importante e requer cuidados especiais para não comprometer o próprio processo de planejamento" (GIACOBBO, 1997, p. 86).

A estratégia no contexto público tem, portanto, como prioridade o bem-estar social e o suprimento das demandas da sociedade. Assim, o planejamento estratégico na perspectiva do setor público deve ser pensado de forma particular e com direcionamento distinto ao das organizações privadas, visto que não há como direcionar o foco somente aos processos e resultados.

\section{Metodologia}

Esta pesquisa classifica-se como um estudo de caso, conforme perspectiva de Yin (2001), por focar uma instituição de ensino superior federal brasileira, e se caracteriza pela abordagem qualitativa. Segundo Richardson (1999, p. 80), “esse tipo metodologia busca descrever a complexidade de determinado problema, analisar a interação de certas variáveis, compreender e classificar processos dinâmicos vividos por grupos sociais". O estudo é classificado também como exploratório e, sob a ótica de Beuren (2008), a pesquisa exploratória tenciona conhecer o tema com maior profundidade, o que permite ao pesquisador ampliar o entendimento sobre o fenômeno investigado, especialmente quando não há muita informação disponível acerca desle.

A pesquisa foi realizada em uma instituição de ensino superior federal de Santa Catarina e teve como objeto de análise o seu processo de planejamento estratégico. A escolha desse órgão se deu pelo fato de que se configura como representante e executora das políticas públicas em educação superior do governo federal em nível regional.

A coleta de dados foi realizada em documentos da instituição pesquisada, documentos oficiais que norteiam as diretrizes da educação nacional e entrevistas semiestruturadas. Trata-se, portanto, de levantamentos de dados primários e secundários. Quanto aos primários, resultam de entrevistadas semiestruturadas com os principais responsáveis pelo planejamento da instituição, nas gestões referentes aos períodos 2008-2011 e 2012-2015. Foram analisados dois períodos 
com o intuito de verificar a continuidade das ações desenvolvidas e objetivando a imparcialidade das informações.

A amostra dos dados primários compõe-se de seis entrevistados ocupantes dos seguintes cargos: pró-reitor de Planejamento Adjunto, pró-reitor de Pesquisa, pró-reitor de Extensão e pró-reitor de Graduação da gestão referente ao período de 2012 a 2016. Além disso, foram entrevistados o secretário de Planejamento da gestão de 2008 a 2012 e o pró-reitor de Graduação do mesmo período. Em relação à Pró-Reitoria de Pesquisa e Extensão da gestão anterior, não se pode obter informações já que tanto a pró-reitora quanto o secretário à época manifestaram não ter interesse em participar da pesquisa. Ressalta-se que o período de gestão foi assim denominado, pois a troca de gestão ocorre sempre no mês de maio. Os períodos analisados referem-se portanto a maio de 2008 a maio de 2012 e maio de 2012 a maio de 2016. A seleção desses cargos se deu em função de que são os que representam funções estratégicas no processo de elaboração e execução do planejamento estratégico da instituição.

No que tange aos dados secundários, foram analisados os principais documentos da instituição relacionados ao processo de planejamento estratégico, como Planos de Desenvolvimento Institucional, Relatórios de Gestão, Estatuto, Regimento Interno e informações disponibilizadas no site institucional referentes aos períodos investigados. Além disso, também foram utilizadas as legislações que regem as instituições de ensino superior (IES) sob esse aspecto. Para tanto, o levantamento dos dados secundários foi feito de forma inicial no primeiro semestre de 2014, e as entevistas, no segundo semestre do referido ano.

Os dados foram examinados de acordo com a categoria de análise que corresponde ao elemento 5 da concepção de governança pública, a saber, planejamento com vistas à equidade e ao desenvolvimento regional. Este elemento foi guiado pelas seguintes subcategorias de análise: (i) capacidade do Estado em adotar critérios de equidade na concepção de projetos, programas e políticas públicas, tendo em conta a evolução divergente de cada região administrativa e, portanto, as suas diferentes necessidades; ii) coerência entre os projectos elaborados e implementados na estrutura estatal 
descentralizada para baixo, e o planejamento de políticas públicas e agendas governamentais destinados em nível do governo central.

\section{APRESEnTAÇÃo E ANÁLISE dos dAdos}

\subsection{0 planejamento estratégico desenvolvido pela IES e sua relação com a ideia de equidade e desenvolvimento regional}

Com base nas informações obtidas referentes aos períodos analisados, o processo de planejamento estratégico tem como base o Plano de Desenvolvimento Institucional (PDI). O documento pode ser ainda definido pelo Ministério da Educação (MEC), com base no art. 16 do Decreto n. 5.773 de 09 de maio de 2006, como aquele que identifica a IES no que diz respeito à sua filosofia de trabalho, à missão a que se propõe, às diretrizes pedagógicas que orientam suas ações, à sua estrutura organizacional e às atividades acadêmicas que desenvolve e/ou que pretende desenvolver (BRASIL, 2006).

De acordo com os entrevistados da área de planejamento em ambas as gestões, o planejamento estratégico da instituição se pauta em diretrizes exigidas pelo Ministério da Educação. Segundo o secretário de Planejamento da gestão 2008-2011, “existem diretrizes do Ministério da Educação que devem ser seguidas e parâmetros contidos na Lei 10.861/2004 e Decreto 5.773/2006 que determinam a elaboração do PDI". Além disso, a atual pró-reitora adjunta afirma que "o PDI é o que há de mais estratégico em termos de planejamento na IES atualmente".

Dessa forma, o PDI representa o resultado do processo de planejamento da instituição e se configura como o que orienta a execução dele. Assim, contempla elementos importantes para o planejamento da IES que acabam por auxiliar nessa função administrativa.

Dessa forma, a IES apresenta no PDI as diretrizes exigidas pela legislação em educação superior, bem como descreve e projeta as atividades que pretende desenvolver em relação a inovações científicas junto aos alunos e à comunidade. Portanto, o planejamento estratégico da instituição é basicamente alicerçado em seu Plano de Desenvolvimento Institucional.

Em relação à execução do planejamento, cada Centro de Ensino deve realizar o acompanhamento de suas ações numa periodicidade 
anual; são publicadas as atividades realizadas em um documento chamado Relatório de Gestão. Segundo a atual pró-reitora de Planejamento, "o PDI aprovado, há discussões em cada Centro de Ensino das ações que são realizadas num período anual para que se cumpram os objetivos estabelecidos no PDI. Este monitoramento é realizado desde 2010 e são publicados nos Relatórios de Gestão".

Havia a ideia durante a gestão anterior, segundo o secretário de Planejamento, de que esse acompanhamento se desse por meio de uma ferramenta virtual denominada "gp web" cujo objetivo era de que as informações fossem atualizadas constantemente e que o processo se tornasse transparente. Segundo os relatos do secretário de Planejamento 2008-2012: “A ideia era de que este processo fosse realizado semestralmente, pois os problemas poderiam ser corrigidos de forma mais dinâmica dentro do próprio ano. No entanto, não houve avaliação das informações alimentadas pelas Unidades de Ensino a fim de corrigir os problemas identificados".

Portanto, essa ferramenta virtual ainda não é utilizada como mecanismo de gestão pela instituição.

O planejamento estratégico da instituição deveria ser realizado num sistema de "janelas", no qual se descarta o ano que já transcorreu e acrescenta-se mais um para o período. Dessa forma, o processo de planejamento não cessaria e não haveria preocupação em planejar somente a cada quinquênio. (SECRETÁRIO DE PLANEJAMENTO 2008-2012)

Tal sugestão possibilitaria um processo contínuo de planejamento, no entanto não se percebe nenhuma ação nesse sentido. Ainda que o período do planejamento estratégico da IES (PDI) não coincida com o mandato da gestão de suas gestões, ele somente é repensado após o término de cada quinquênio, o que não o torna um processo contínuo.

No caso da IES pesquisada, é preciso que o planejamento seja visto como uma atividade sistematizada de gestão dela, e não apenas como uma formalidade que deve ser cumprida por cada gestão que a representa. 


\subsection{Capacidade da IES em adotar critérios de equidade na concepção de projetos, programas e políticas públicas, tendo em conta a evolução divergente de cada região administrativa}

Sob a ótica desse eixo de análise, nota-se que a instituição acompanha as decisões do governo federal. Segundo a atual pró-reitora adjunta de Administração, "a Universidade acaba sendo meio para o desenvolvimento da região, mas não cabe a ela tal decisão". Nesse sentido, o planejamento das ações em prol do desenvolvimento regional em ambas as gestões está relacionado ao Programa de Apoio a Planos de Reestruturação e Expansão das Universidades Federais (Reuni), instituído pelo Decreto n. 6.096, de 24 de abril de 2007, como medida de expansão da educação superior, tendo como principal objetivo ampliar o acesso e a permanência na educação superior.

Segundo a pró-reitora adjunta de Planejamento da gestão 2012-2016,

o programa REUNI foi um grande momento de criação de cursos na IES, que se deu por uma determinação mais política de criação dos campi [...] no entanto, como foi implantado dois anos depois, podese ouvir a comunidade e estudar as potencialidades da região para implantação de cursos voltados para o desenvolvimento da região.

Corroborando essa linha de pensamento, o pró-reitor de Graduação do mesmo período afirma que "a ideia da implantação dos campi em outras cidades está intimamente ligada ao desenvolvimento dessas regiões, inclusive o projeto pedagógico dos cursos tem este intuito. Mais do que levar a educação superior ao interior, pretende-se desenvolver as regiões envolvidas no processo".

Em relação à adoção de critérios de equidade, o pró-reitor de Extensão da gestão 2012-2016 informa que há um trabalho em conjunto com o governo do Estado para o desenvolvimento das potencialidades nos municípios com baixo IDH, refletindo a visão de equidade entre as regiões.

A ideia de médio/longo prazo é que sejam mapeadas junto ao governo do Estado as regiões com baixo IDH, por exemplo, para que sejam 
priorizadas ações de extensão para o desenvolvimento dessas regiões. Assim, o conhecimento científico e tecnológico seria utilizado como meio de desenvolver as regiões com a criação de mais empregos e potencialidades. (PRÓ-REITOR DE EXTENSÃO 2012-2016)

Uma questão importante apontada pelo pró-reitor de Extensão (2012-2016) é a consolidação de parcerias com as prefeituras. Assim, pode-se desenvolver as regiões em que a IES atua de forma mais equânime, já que nem todos os municípios estão preparados para o desenvolvimento.

A preocupação se dá no sentido de que existem regiões em que a resposta às ações ocorre de forma mais rápida pela vocação ou experiência do município. Ressalta-se neste caso a importância de parcerias com as prefeituras, haja vista que as mesmas detêm maior conhecimento das especificidades dos seus problemas. (PRÓ-REITOR DE EXTENSÃO 2012-2016)

Conforme apontado por Dias (2012), Cario e Dias (2014), regiões e outras unidades geográficas evoluem em ritmos e formas diferentes, demandando, nesse sentido, um jeito diferente de governar e um planejamento que leve em consideração as questões sociais específicas. Assim, se percebe que há a perspectiva de contribuir para desenvolvimento regional, mas que a função planejamento da IES ainda está mais voltada ao atendimento de exigências legais e ao alinhamento de seus projetos. Apesar disso, existe a preocupação de que se faça um planejamento de atividades com critérios mais equânimes, considerando a evolução divergente de cada região e suas diferentes necessidades.

\subsection{Coerência entre os projetos elaborados pelo governo federal e implementados pela IES}

Verifica-se que a instituição planeja suas ações em função das diretrizes estabelecidas para a educação nacional. A fala do pró-reitor de Pesquisa referente à gestão de 2012-2016 reflete a condução das atividades na IES, a partir do que o governo federal coloca como prioritário: 
Existem diretrizes gerais de pesquisa para as Universidades Federais e, pelo fato de se saber que há recursos que serão alocados nessas linhas, a IES muitas vezes se adapta a estas no intuito de fomentar a pesquisa na instituição. [...] De uma maneira geral os cursos são criados a partir de exigências e incentivos do MEC.

Nesse sentido, o pró-reitor de Extensão (2012-2016) diz que a ideia da Pró-Reitoria de Extensão é implementar programas que vinculem os projetos existentes às linhas discutidas no Fórum Nacional de Pró-Reitores de Extensão. Dessa forma, os projetos de extensão estariam contemplados no planejamento estratégico da instituição que, por sua vez, se alinharia aos programas nacionais.

Além disso, segundo o pró-reitor de Extensão (2012-2016), “o planejamento estratégico na IES ainda é um processo recente e pelo fato de os projetos de extensão ocorrerem de forma pontual, como iniciativa de grupos de pesquisa, não há conhecimento de toda a comunidade acadêmica".

Percebe-se, portanto, que as ações de planejamento estratégico da IES alinham-se às diretrizes do governo federal nas principais áreas de atuação da instituição. Nota-se ainda que há poucas iniciativas dela em desenvolver atividades que não estejam sob alguma exigência vinculada ao governo federal.

\subsection{Características de governança pública verificadas no planejamento estratégico da IES}

Observa-se que durante o processo de planejamento existe a participação de todas as instâncias da IES, bem como a realização de consultas públicas. Assim, há a participação da sociedade na elaboração do planejamento da instituição.

Para a elaboração do PDI, tanto a pró-reitora Adjunta de Planejamento (2012-2016) quanto o secretário de Planejamento (2008-2012) afirmam ser um processo que se dá de forma participativa com o envolvimento das principais instâncias da IES (alunos, professores e técnicos administrativos) e com o máximo de representatividade. A pró-reitora adjunta de Planejamento 20122016 relata que: “[...] há a atuação das unidades administrativas e acadêmicas (Centros de Ensino). Assim, constitui-se uma comissão 
com os representantes citados que estudam as principais diretrizes do planejamento [...]".

Nota-se que há participação de todas as instâncias da IES na elaboração do planejamento, incluindo a realização de consultas públicas para sua aprovação. De acordo com Ronconi (2008), a governança pública se dá em um arranjo ou formato institucional governamental que, pautado em um projeto democrático, põe ênfase na gestão compartilhada, na geração de uma cultura participativa e no aprofundamento e consolidação da democracia.

Outra característica verificada é a preocupação com o entorno da instituição. Segundo o secretário de Planejamento (2008-2012), "um dos objetivos propostos no PDI era trabalhar o entorno da instituição até na forma de balanço social, explicitando o que de fato está sendo oferecido à comunidade, já que uma das dimensões do PDI é o Social".

Ao delinear a ideia de participação social, Bevir (2010) afirma que a efetividade das instituições políticas depende da incorporação de diversos atores interessados dentro dos processos de decisão. Vê-se, portanto, que a participação social transcende ao âmbito da mera consulta, possibilitando uma relação de diálogo mais ativa com a sociedade.

Nessa perspectiva, no que tange à participação da sociedade no planejamento da instituição ainda há avanços que precisam ser feitos, pois de acordo com Secchi (2009, p. 349), “a governança pública se traduz em um modelo relacional porque oferece uma abordagem diferenciada de conexão entre o sistema governamental e o ambiente que circunda o governo".

Assim, percebe-se que o processo de planejamento estratégico da IES é baseado em um documento exigido pela legislação nacional e que ela vincula as diretrizes advindas do governo federal ao seu planejamento. Há iniciativas e discussões em todas as Pró-Reitorias consultadas visando a aproximar o processo de planejamento a elementos do movimento de governança pública. Percebe-se o esforço em fomentar ideias e materializar estruturas de gestão mais voltadas à governança. Entretanto, ainda há um longo caminho a ser percorrido. 
Dessa forma, a IES federal tem em suas ações elementos que se aproximam da concepção de governança pública. Ao entenderse como representante do governo federal em educação superior e elaborar seu planejamento estratégico com parâmetros que refletem os programas nacionais, demonstra alinhamento à função planejamento preconizada pela concepção de governança pública (CARIO; DIAS, 2014).

\subsection{Recomendações de melhoria ao planejamento estratégico da IES à luz do movimento de governança pública}

O processo de planejamento estratégico da instituição está mais voltado para ações internas, ainda que haja preocupação em solucionar problemas que resultem em benefícios à sociedade. Segundo a pró-reitora adjunta de Planejamento (2012-2016), "basicamente o planejamento da IES é voltado para ações internas e de gestão".

Há iniciativas pontuais e de algumas Pró-Reitorias em atender a demandas da sociedade, mas percebe-se que ainda não é uma política institucional. É mister ampliar o debate acerca da inserção social, o que permitirá o aperfeiçoamento da prática de governança pública na instituição. Entretanto, cabe ressaltar que, ainda que a organização não planeje suas ações sob um olhar voltado aos anseios da sociedade, uma vez que a instituição se preocupa e valoriza sobretudo as suas atividades internas (como os cursos de graduação, por exemplo), estas acabam por impactar de forma relevante o desenvolvimento da sociedade.

Como forma de melhorar a transparência entre a instituição e a sociedade, sugere-se que seja implementado o Balanço Social discutido pelo pró-reitor de Planejamento (2008-2012) como ferramenta de gestão que aborde as ações desenvolvidasna sociedade, auxiliando a IES no sentido de acompanhar e divulgar as atividades executadas.

Ressalta-se também que na gestão referente ao período de 2008-2012, havia a ideia de que fosse constituído um conselho consultivo com a participação da sociedade civil, até mesmo Conselho Universitário. Segundo o secretário de Planejamento (2008-2012),

a proposta era de ser criado um conselho consultivo com a participação da sociedade civil. A ideia era de que houvesse um envolvimento 
dos conselhos de classe e de representantes da sociedade no Conselho Universitário para atendimento das demandas da sociedade e planejamento das ações a serem realizadas.

Com a mudança de gestão na IES, se percebe que não houve mais discussões a respeito da implementação do conselho nesses moldes. Acredita-se que com a participação mais intensa da sociedade - por exemplo, com representantes no Conselho Universitário - se possa dar passos significativos rumo à consecução de uma gestão mais participativa e construída de forma consensada. Nota-se que a Instiuição prevê em sua estrutura elementos que formalizam essa participação da sociedade, no entanto tal interação encontra-se muito mais no formalismo e pouco foi materializado.

Destaca-se também que a execução das atividades, principalmente as relacionadas ao atendimento de demandas da sociedade, não é realizada de forma sistematizada e há pouco acompanhamento da instituição. Segundo a pró-reitora adjunta de Planejamento (2012-2016), "há uma descentralização muito grande dos projetos realizados e, portanto, não há acompanhamento por parte da Pró-Reitoria de Planejamento neste sentido".

No entanto, havia na gestão de 2008-2012 a ideia de que as informações relacionadas ao planejamento estratégico da IES fossem alimentadas em uma ferramenta que proporcionaria maior transparência das ações e auxiliaria na gestão da Instituição, uma vez que a avaliação dos projetos seria realizada de forma sistematizada. Segundo o secretário de Planejamento 2008-2012,

Uma vez alimentado o "gp web", tornariam públicas as ações realizadas e ficaria mais ágil avaliar o planejamento estratégico da IES como um todo. A ideia era de que este processo fosse realizado semestralmente, pois os problemas poderiam ser corrigidos de forma mais dinâmica dentro do próprio ano. No entanto, não houve avaliação das informações alimentadas pelas unidades de ensino a fim de corrigir os problemas identificados.

Dessa forma, em certa medida fica evidenciada a fragilidade no acompanhamento dos processos de gestão, bem como dos projetos 
articulados entre a comunidade. O pró-reitor de Pesquisa (2012-2016) diz ainda que "há projetos individuais de professores e grupos de pesquisa e outros que não estão vinculados à Pró-Reitoria, portanto, não há como acompanhar todos os resultados".

O acompanhamento de resultados acaba sendo vinculado à prestação de contas dos projetos executados. De acordo com pró-reitor de Extensão (2012-2016) “existe o Relatório de Gestão que contempla as ações realizadas e, portanto, serve como instrumento de avaliação das ações anteriormente planejadas".

O pró-reitor de Pesquisa (2012-2016) afirma ainda que "o próprio relatório técnico que se elabora ao final de cada projeto funciona como uma maneira de avaliar se o projeto foi cumprido de forma satisfatória".

Assim, a implantação de uma ferramenta como o "gp web", por exemplo, poderia ser uma alternativa para o acompanhamento e avaliação dos projetos que estão sendo executados pela instituição.

Percebe-se, portanto, que ainda há fragilidades na participação da sociedade e do setor privado no acompanhamento do planejamento estratégico. A ideia do estabelecimento de um conselho consultivo poderia ser um caminho importante na consecução de maior participação social. Além disso, os projetos estão sendo realizados de forma individualizada, pontual e sem maior conhecimento e/ou planejamento por parte da instituição. É importante que se considere a implantação de um sistema que reúna os projetos e atividades gerenciais, pois, além de divulgar as atividades realizadas a toda a comunidade acadêmica (público interno e comunidade), permitiria maior transparência no acompanhamento de todos os processos.

Recomenda-se ainda o fortalecimento de parcerias com empresas privadas e com outros órgãos públicos com o intuito de fortalecer ainda mais a articulação com os atores que compõem a sociedade e que podem contribuir de forma substancial para o desenvolvimento das regiões nas quais os programas e projetos forem desenvolvidos.

\section{ConCluSÃo}

Este estudo buscou analisar o processo de elaboração e execução do planejamento estratégico da instituição de ensino superior 
federal pesquisada à luz de critérios de planejamento abordados na concepção de governança pública neodesenvolvimentista.

Para tanto, foram coletados dados primários e secundários com o intuito de responder aos objetivos: i) conhecer o processo de elaboração e execução do planejamento estratégico da instituição de ensino superior pesquisada; ii) verificar a aplicação das características de governança pública no planejamento estratégico da instituição de ensino superior; e iii) apontar recomendações de melhoria no planejamento estratégico da instituição de ensino superior à luz do movimento de governança pública.

Em relação ao processo de elaboração e execução do planejamento estratégico da instituição, os resultados demonstraram que se trata de um processo recente e que a IES tem no Plano de Desenvolvimento Institucional as principais ações a serem realizadas por um período de cinco anos. Todas as atividades a serem desenvolvidas são guiadas pelo documento criado a partir de uma exigência legal, a saber, a Lei n. 10.861/2004 e o Decreto 5.773/2006). O seu processo de elaboração se deu de forma participativa com o envolvimento das principais instâncias da IES (alunos, professores e técnicos administrativos) e com o máximo de representatividade, além de consultas públicas. No que tange a sua execução, existem iniciativas voltadas para uma aplicação integral e sistematizada. No entanto, ainda há fragilidades no acompanhamento das ações planejadas.

Destaca-se também que há descontinuidade em relação a ideias e projetos a serem implementados. Observou-se que algumas iniciativas de aperfeiçoamento no planejamento estratégico não foram levadas adiante de uma gestão para outra, o que demonstra que a IES ainda não o vê de forma sistematizada e institucional.

Sobre a vinculação do planejamento estratégico da instituição com as concepções de equidade e desenvolvimento regional, notou-se que a orientação dela em adotar critérios de equidade na concepção de projetos, programas e políticas públicas, tendo em conta a evolução distinta de cada região administrativa, não indica maior desprendimento em relação as políticas governamentais. Isto é, por um lado a instituição é um importante meio para o desenvolvimento das regiões; por outro, ela ainda carece de maior autonomia na tomada de uma decisão de significativo impacto social. 
No entanto, apesar de não caber somente à instituição a iniciativa de desenvolver as regiões nas quais atua, há discussões na direção da promoção de parcerias com os municípios por meio das quais a IES pode tornar-se cada vez mais um meio de promoção do desenvolvimento de regiões, sobretudo daquelas que apresentam maiores carências e vulnerabilidades. Ações desse tipo poderiam contribuir sobremaneira com a consolidação de um modelo de desenvolvimento mais equânime das regiões do Estado.

Já em relação ao segundo eixo de análise, verifica-se que a instituição planeja suas ações em função das diretrizes estabelecidas para a educação nacional. Percebe-se que ela adapta o planejamento à sua realidade, a partir do que é exigido pelos instrumentos legais. A fala do pró-reitor de Pesquisa referente a gestão de 2012-2016 reflete a condução das atividades na instituição, a partir do que o governo federal coloca como prioritário. “Existem diretrizes gerais de pesquisa para as Universidades Federais e, pelo fato de se saber que há recursos que serão alocados nessas linhas, a IES muitas vezes se adapta a estas no intuito de fomentar a pesquisa na instituição".

Destaca-se ainda a presença de características do movimento de governança pública como: olhar para as demandas da sociedade preconizando o bem comum; presença de redes e parcerias; e elementos de democracia e transparência que podem ser verificadas no processo de planejamento estratégico da Instituição.

O fato de a IES considerar no PDI a dimensão social e discutir a necessidade de uma gestão que tenha por finalidade o atendimento de demandas sociais revela a sua aderência à ideia de bem comum tal qual preconizada pela governança pública. Como dito por Heinemann e Kissler (2006), a orientação de ação para o bem comum é o diferencial da governança pública.

Por ser uma instituição que atua como representante do governo federal em educação superior, a IES contempla em seu planejamento estratégico normas e diretrizes nacionais. E mais, atua com parcerias com outros órgãos estatais e também com o setor privado, o que revela que ela valoriza a configuração de redes e parcerias em seu processo de planejamento estratégico.

Kooiman (2003) ratifica que o movimento de governança pública se estabelece por meio de uma interação entre os diferentes 
atores (e sua interdependência). Essas correlações se constituiriam, ao fim e ao cabo, como elementos imprescindíveis na consolidação de padrões de maior sustentabilidade para a sociedade.

Pode-se indicar também a presença de elementos democráticos na elaboração do planejamento estratégico da IES, uma vez que há consultas públicas junto a sociedade. Cabe destacar que a referida participação é vista na elaboração do PDI. Apesar disso, não há um acompanhamento integral, constante, por parte da comunidade.

Em coerência com os preceitos públicos e democráticos, urge maior acompanhamento da sociedade. Como lembra Dias (2012), o movimento de governança pública é baseado na ideia de que os cidadãos podem e devem ser envolvidos na construção e na implementação das políticas públicas. E mais, uma proposta de fortalecimento democrático vem fomentando a Administração Pública a partir da ideia de maior inclusão da sociedade civil e, assim, das comunidades locais.

No entanto, apesar de verificar-se a existência de características de um movimento de governança pública neodesenvolvimentista, que tem em seu planejamento estratégico ações que venham ao encontro da ideia de equidade e desenvolvimento regional, percebe-se que a gestão da Instituição ainda é fortemente marcada pelo canon gerencialista.

Ao afirmar que "basicamente o planejamento da IES é voltado para ações internas e de gestão", a Pró-Reitora Adjunta de Planejamento (2012-2016) confirma que a IES planeja suas ações com um olhar voltado aos resultados dos processos gerenciais. Conforme afirma Secchi (2009), no gerencialismo as práticas administrativas se voltam aos resultados. Portanto, o planejamento estratégico da instituição está mais voltado para resultados gerenciais, sob uma perspectiva gerencialista, não levando tanto em consideração os aspectos sociais. Como asseveram Cario e Dias (2014), o movimento de governança pública neodesenvolvimentista preconiza que a função planejamento fica mantida em relação ao movimento gerencialista, no entanto, com aderência ao contexto regional e preocupação com os problemas sociais.

Sobre recomendações de melhoria no planejamento estratégico da instituição à luz do movimento de governança pública neodesen- 
volvimentista, verificou-se que durante a execução do planejamento houve pouca participação da sociedade, limitando-se ao momento de elaboração. Além disso, percebeu-se que o processo, num todo, é pouco transparente.

Dessa forma, pontos como a participação democrática e a transparência ainda não estão consolidados na execução do planejamento estratégico da IES. Sugere-se, então, a criação de conselhos consultivos e ferramentas administrativas que auxiliem na divulgação e acompanhamento do planejamento estratégico dela. Por exemplo, a implantação do "gp web" e do balanço no intuito de: 1) fomentar maior envolvimento da sociedade; e 2) criar condições para que a gestão da IES se consolide, cada vez mais, como prática de governança pública.

Também recomenda-se que haja mais parcerias e convênios com empresas privadas e com outros órgãos públicos com o intuito de fortalecer ainda mais a articulação com os atores que compõem a sociedade e que podem contribuir de forma substancial para o desenvolvimento das regiões nas quais os programas e projetos forem desenvolvidos.

Como o PDI é elaborado a cada quinquênio, o documento referente ao planejamento da atual gestão ainda não está totalmente finalizado, visto que se refere ao período de 2015 a 2019.

Como sugestão para próximos estudos, propõe-se que sejam aplicadas pesquisas que levantem informações também na comunidade, ampliando a visão de planejamento para além dos gestores e dos que estão dirigindo a instituição. Além disso, se sugere que sejam realizadas pesquisas em outros órgãos públicos.

\section{REFERÊNCIAS}

BEUREN, I. M. Como elaborar trabalhos monográficos em contabilidade: teoria e prática. 3. ed. São Paulo: Atlas, 2008.

BEVIR, M. Democratic Governance. New Jersey: Princeton, 2010.

BRASIL. Decreto n. 5.773, de 09 de maio de 2006. Diário Oficial da União, Poder Executivo, Brasília, DF, 10 maio 2006. Disponível em: <http://www2.mec.gov.br/sapiens/portarias/dec5773. htm>. Acesso em: 12 maio 2016. 
CARIO, S. F.; DIAS, T. Sociedade, desenvolvimento e o papel estratégico do Estado: uma reflexão sobre o surgimento da governança pública. Ensaios FEE [Impresso], v. 35 (n.2), p. 337-362, 2014.

DENHARDT, R. Teoria Geral de Organizações Públicas. Tradução de Francisco G. Heidemann. 6. ed. São Paulo: Cengage Learning, 2012.

DIAS, T. Governança Pública: uma concepção teórico-analítica aplicada no governo do Estado de Santa Catarina a partir da implantação das Secretarias de Desenvolvimento Regional. 356 f. Tese (Doutorado em Administração) - Programa de Pós-Graduação em Administração, Universidade Federal de Santa Catarina, Florianópolis, 2012.

COUTINHO, C. N. (Org.) O leitor de Gramsci. Escritos escolhidos: 1916-1935. Rio de Janeiro: Civilização Brasileira, 2011.

GIACOBBO, M. O desafio da implementação do planejamento estratégico nas organizações públicas. Revista do TCU, Brasília, v. 28, n. 74, p. 73-107, out./dez. 1997.

GUERALDI, R. G. A interface entre os setores público e privado: uma perspectiva estratégica. Salvador: ENAMPAD, 2006.

HEGEL, G. W. F. Princípios da filosofia do direito. São Paulo: Martins Fontes, 2000.

KISSLER, L.; HEIDEMANN, F. G. Governança pública: novo modelo regulatório para as relações entre Estado, mercado e sociedade? Revista de Administração Pública, Rio de Janeiro, v. 40, n. 3, p. 479-499, maio/jun. 2006.

KOOIMAN, J. Governing as Governance. Londres: Sage, 2003.

MOTTA, P. R. A modernização da administração pública brasileira nos últimos 40 anos. Revista de Administração Pública, v. 41(n. especial), p. 87-96, 2007.

PEREIRA, S. C. de S. O planejamento estratégico em organizações públicas: um estudo de caso das organizações militares prestadoras de serviço. In: CONGRESO INTERNACIONAL DEL CLAD SOBRE LA REFORMA DEL ESTADO Y DE LA ADMINISTRACIÓN PÚBLICA, 11., 2006, Ciudad de Guatemala. Anais... Ciudad de Guatemala, 2006.

RAMOS, A. G. A nova ciência das organizações. Rio de Janeiro: Editora da FGV, 1989.

RAQUEL, I. Governança pública: A consolidação de uma matriz com atributos que caracterizam o tema, na perspectiva de especialistas. 175 f. Dissertação (Mestrado em Administração) - Programa de Pós-Graduação em Administração, Universidade Federal de Santa Catarina, Florianópolis, 2012.

RICHARDSON, R. J. et al. Pesquisa social: métodos e técnicas. 3. ed. São Paulo: Atlas, 1999.

RONCONI, L. F. de A. A Secretaria Nacional de Economia Solidária: uma experiência de governança pública. 279 f. Tese (Doutorado em Sociologia Política) - Programa de Pós-Graduação em Sociologia Política, Universidade Federal de Santa Catarina, Florianópolis, 2008.

SECCHI, L. Modelos organizacionais e reformas da administração pública. Revista de Administração Pública, Rio de Janeiro, v. 43, n. 2, p. 347-69, mar./abr. 2009.

YIN, R. K. Estudo de caso: planejamento e métodos. Porto Alegre: Bookman, 2001. 
Planejamento estratégico de uma instituição de ENSino Superior FEDERAL BRASILEIRA: UMA ANÁLISE À LUZ DO MOVIMENTO DA GOVERNANÇA PÚBLICA

Recebido em: 08-03-2017

Aprovado em: 24-04-2017

Avaliado pelo sistema double blind review.

Editor: Elmo Tambosi Filho

Disponível em http://mjs.metodista.br/index.php/roc 